\title{
Evaluation of the correlation between serum lipid characteristics of obese subjects and ADIPOQ gene rs266729 polymorphism in Chaharmahal and Bakhtiari Province of Iran
}

\author{
Negar Rabiee', Roohollah Nakhaei Sistani1, Ali Mohammad Ahadi²,*, Reza Baharloo3 \\ ${ }^{1}$ Department of Cellular and Molecular Biology, Faculty of Chemistry, Kashan University, Kashan, Iran \\ ${ }^{2}$ Department of Genetics, Faculty of Science, Shahrekord University, Shahrekord, Iran \\ 3 Department of Medical Laboratory Sciences, Shahrekord University of Medical Sciences, Shahrekord, Iran
}

\begin{abstract}
Obesity is a multifactorial disorder that is influenced by various factors such as behavior, diet, environment, metabolic and genetic. This disease is the result of an imbalance between energy absorption and expenditure. Mutations in genes that are responsible for appetite control and metabolism are considered as the genetic component of obesity. Adiponectin protein is one of the most effective adipokines in regulating the body's energy homeostasis and fat storage, which is expressed by the ADIPOQ gene and secreted from white adipose tissue. The concentration of this protein in the blood decreases in obesity. In this study, the relationship between rs266729 $(-11,377 \mathrm{C}>\mathrm{G})$ polymorphism in the ADIPOQ gene with the level of biochemical parameters such as total cholesterol and triglyceride and HDL and LDL in the blood of obese people in Borujen (a city in Iran) was investigated. This study was performed on 100 people who referred to the Tamin Ejtemaee clinic due to obesity problems in Borujen. In this study, the ARMS-PCR method was used to determine the genotype of individuals. Based on the results of this study, no significant relationship was found between biochemical parameters including total cholesterol, triglyceride, and LDL with rs266729 polymorphism genotypes in ADIPOQ gene in obese subjects. We concluded that rs266729 polymorphism cannot be useful as an index parameter for predispose genotype for imbalance in total cholesterol, triglyceride, and LDL levels in a person.
\end{abstract}

Keywords: Obesity, ADIPOQ gene, Cholesterol, Triglyceride

\section{Introduction}

Obesity is an epidemic disorder in the 21st century. According to epidemiological studies, the prevalence of overweight/obesity has been estimated to have increased by $41 \%$ from 1980 to $2013(1,2)$. Obesity is an important issue for the public health organization because obesity and overweight increase the risk of several serious chronic diseases such as type 2 diabetes, cardiovascular disease, hypertension and stroke, hypercholesterolemia, hypertriglyceridemia, osteoarthritis, asthma, and certain types of cancer (3). Obesity phenotype occurs when food intake constantly exceeds energy expenditure, resulting in a positive long-term energy imbalance (1). Overeating and decreased physical activity are two common causes of obesity, but in addition to them, decreased diversity of intestinal microflora, sleep deprivation, and endocrine disorders are also among the effective factors in

\footnotetext{
* Corresponding author:

Dr. Ali Mohammad Ahadi, Ph.D

Department of Genetics, Faculty of Science,

Shahrekord University, Shahrekord, Iran

Tel/Fax: +98 3832324419

Email: Ahadi_al@sku.ac.ir

https://orcid.org/oooo-0001-9580-2740
}

Received: September, 27, 2020

Accepted: October, 23, 2020 
increasing the prevalence of obesity (4). Scientists around the world have intensified their efforts to elucidate the pathophysiological mechanisms which lead to obesity or reinforce its main consequences, to create effective treatments for obesity and related disorders. In this process, the concept of adipocytokines has been defined and dysfunction of adipocytokine pathways has been identified as an important factor in obesity-related disorders. Also, the logical manipulation of adipocytokines is becoming a promising way to treat obesity and its metabolic abnormalities (5).

Since adipokines regulate several important metabolic pathways, genetic variants that affect their function and efficiency may be involved in a variety of pathophysiological conditions. There is evidence that genetic variants in adipokine genes can modulate circulating adipokine levels, which can result in a specific metabolic change (e.g., obesity, insulin resistance, etc.). Therefore, a comprehensive analysis of genetic variants, including various and rare single nucleotide polymorphisms, may provide new insights into the specific role of studied adipokines in the pathophysiology of metabolic diseases (6).

Adiponectin is an adipokine that is mainly secreted from adipocytes $(7,8)$ and its expression is reduced in obesity (9). Human adiponectin is encoded by the ADIPOQ gene with the access number of NM_001177800 for mRNA in the NCBI Genomic Database. This gene is located at chromosomal locus $3 q 27$ (chromosomal locus NC_ooooo3.12) $(5,10,11)$. Circulating adiponectin may act as a biomarker, and its decreased circulating levels may play a mediating role in the pathophysiology of type 2 diabetes, metabolic syndrome, obesity, and atherosclerosis $(7,12)$. This plasma protein increases fatty acids oxidation and reduces circulating fatty acids concentration (13).

Regarding the effect of adiponectin on lipid metabolism, adiponectin may increase HDLc levels. Also, adiponectin can inhibit the catabolism of triglyceride-rich lipoproteins, and consequently lowering triglyceride levels (14). However, in one meta-analysis, no association was reported between adiponectin gene polymorphisms and lipids (15). In general, adiponectin is negatively correlated with HDLc and positively correlated with LDLc and triglyceride concentrations (16). A positive correlation has also been reported between adiponectin and lipoprotein lipase (17). A similar association has been reported between adiponectin, HDLc, and triglyceride in adolescent and postmenopausal women (18). Even in the elderly, adiponectin is positively associated with HDLc and the TC/LDLc ratio (19). However, in patients with type 2 diabetes mellitus (T2DM), conflicting results have been reported due to the association between adiponectin, HDLc, and triglycerides $(20,21)$. HDL dysfunction may be involved in increasing the risk of cardiovascular disease (CVD). Adiponectin is involved in increasing HDL particle size and thus improves HDL quality (22).

Due to the contradictory results observed in the effect of adiponectin gene on the level of serum lipid profiles in obese and other metabolic diseases, in this study, we aimed to investigate the correlation between rs266729 polymorphism of the adiponectin gene and the level of serum lipid characteristics of obese individuals in Southwest of Iran.

\section{Materials and methods}

\subsection{Patients and control group}

Participants in this study were selected based on the criteria defined in the World Health Organization for obesity. Therefore, subjects with $\mathrm{BMI} \geq 30$ were included in our study. Participants did not have underlying diseases, like diabetes. The study protocol was approved by the ethics committee of the Kashan University of Science according to the Declaration of Helsinki and written informed consent was obtained from each subject.

\subsection{Sampling and measurement of biochemical characteristics \\ In this study, blood samples were taken from 100 individuals who had referred to the Tamin Ejtemaee Clinic, Borujen, Charmahal Va Bakhtiari province, Iran, due to the obesity problem. Biochemical parameters such as total cholesterol, triglyceride, HDL, and LDL levels were measured by an autoanalyzer (Alpha-6-ISFAHAN SANJESH Equipment Company, Iran).}

\subsection{DNA extraction and genotyping}

DNA extraction was performed by the phenolchloroform method from whole blood samples and the ARMS-PCR method was used to determine the genotype of individuals. This method is a specific allelic PCR for wild type and mutant sequences that 
use specific primers. In the ARMS-PCR method, two complementary reactions are performed for the detection of each allele in polymorphism. One of the reactions involves a specific primer for the mutant allele and the other contains a specific primer for the wild type allele (23). This method is one of the most suitable methods for detecting known mutations and is based on the $3^{\prime}$ end nucleotide of the primers. In other words, if this nucleotide is the complementary base of the target base, a PCR product would be obtained, otherwise, the product would not be seen in the gel, and a product for a primer that its 3 ' end complementary of another allele must be detected. If PCR products are present in both cases, the person would be heterozygous. The absence of the product in both cases of primers indicates a technical problem in PCR and the lack of optimal conditions. Many studies can be mentioned regarding the application of the ARMS technique. Also, a comparison of the advantages of this technique has been considered in some researches and its applicability in molecular detection has been proven (24-26). To perform this technique, 4 primers were designed using Gene runner software (version 6.5.51 Beta) including two specific primers for the detection of wild type and mutated alleles and two other primers for both sides of the amplicon. The names and sequences of the primers are given in Table 1. In this study, the final volume of the reaction mixture in each microtube was considered to be $25 \mu \mathrm{l}$ and a separate PCR reaction was used to identify each of the $\mathrm{C}$ and $\mathrm{G}$ alleles. The amount of substances used in each of the reactions was as follows: the concentration of substances used to detect the G allele; PCR 1 X buffer, magnesium chloride $1.5 \mathrm{mM}$, dNTP $200 \mu \mathrm{M}$, forward primer $0.4 \mu \mathrm{M}$, reverse primer specific for $\mathrm{G}$ allele $0.4 \mu \mathrm{M}$, template DNA 0.1-1 $\mu \mathrm{g} / \mathrm{ml}$, Taq DNA polymerase $1 \mathrm{U}$ (Sinagen Company, Iran), the concentration of substances in the PCR reaction for detection of the $\mathrm{C}$ allele is the same. The PCR reaction was started with initial denaturation for 5 minutes at $94^{\circ} \mathrm{C}$ and followed by 35 cycles of 3 steps consisted of denaturation at $94^{\circ} \mathrm{C}$ for 30 seconds, annealing at 55 for the $\mathrm{G}$ allele, and at $58^{\circ}$ $\mathrm{C}$ for the $\mathrm{C}$ allele for $4 \mathrm{O}$ seconds and elongation step at $72^{\circ} \mathrm{C}$ for 30 seconds. Finally, the final extension was performed at $72{ }^{\circ} \mathrm{C}$ for 5 minutes. After the ARMSPCR reaction, the samples were run on $2 \%$ agarose gel. ARMS-PCR product length was $115 \mathrm{bp}$ for $\mathrm{G}$ allele and $211 \mathrm{bp}$ for $\mathrm{C}$ allele identification.

\subsection{Statistical analysis}

In this study, SPSS ver. 26 software (IBM Corp., USA) was used for statistical analysis. KolmogorovSmirnov test was used to calculate the normality of data distribution and the ANOVA parametric test was utilized to calculate the significance of data with normal distribution and the Kruskal-Wallis nonparametric test was used for data with a normal distribution. Tukey and LSD tests were also employed to evaluate the significant relationship between biochemical characteristics and each of the polymorphism genotypes. In all tests, a P value of less than 0.05 showed a significant difference between the two groups.

Table 1. Names and sequences of primers

\begin{tabular}{lr} 
Name & Sequence \\
\hline FNRA377 & 5'-CCTTTCTCACCCTTCTCACC-3' \\
\hline RNRB377 & 5'-CGCCCATGTTTTGTTTTTGAAGC-3' \\
\hline FNRC377 & 5'-GAACCGACTCAGATCCTGCC-3' \\
\hline RNRD377 & 5'- GCCTGGAGAACTGGAAGCTG -3' \\
\hline
\end{tabular}

\section{Results}

Demographic information and mean serum lipid profile levels of obese individuals are listed in Table 2. Data normality was assessed using the KolmogorovSmirnov test. HDL and LDL indices had a normal distribution and total cholesterol and triglyceride indices had abnormal distribution. Therefore ANOVA test was used to evaluate the significant relationship between HDL and LDL indices and the Kruskal-Wallis test was utilized to evaluate the total cholesterol and triglyceride indices (Table 3). According to Table 3, no significant correlation was found between biochemical characteristics consisted of the levels of cholesterol ( $\mathrm{P}$ $=0.182)$, triglyceride $(\mathrm{P}=0.431), \mathrm{HDL}(\mathrm{P}=0.451)$ and LDL $(\mathrm{P}=0.188)$ and CC, CG and GG genotypes of ADIPOQ rs266729 polymorphism.

In this study, the collected data were analyzed by Tukey and LSD methods. These two methods focus on comparing means, while ANOVA and Kruskal-Wallis tests focus on the variance of the whole data. Tables 4 and 5 show the results of Tukey and LSD tests for rs266729 polymorphism. According to the results of these tests, no significant correlation was found 


\section{Rabiee et al.}

between any of the CC, CG, GG genotypes of ADIPOQ rs266729 polymorphism, and biochemical characteristics including total cholesterol, triglyceride, HDL, and LDL levels in obese subjects.

Table 2. Mean parameters measured in obese subjects

\begin{tabular}{|cc|}
\hline Parameter & $\begin{array}{c}\text { Obese subjects } \\
\text { Mean } \pm \text { SD }\end{array}$ \\
\hline Gender $($ Male/Female) & $52 / 48$ \\
\hline Age $(\mathrm{year})$ & $50.19 \pm 13.42$ \\
\hline BMI $(\mathrm{kg} / \mathrm{m} 2)$ & $39.77 \pm 5.03$ \\
\hline Total cholesterol $(\mathrm{mg} / \mathrm{dl})$ & $236.05 \pm 31.55$ \\
\hline Triglyceride $(\mathrm{mg} / \mathrm{dl})$ & $238.96 \pm 99.68$ \\
\hline HDL $(\mathrm{mg} / \mathrm{dl})$ & $41.57 \pm 11.85$ \\
\hline LDL $(\mathrm{mg} / \mathrm{dl})$ & $146.55 \pm 31.18$ \\
\hline
\end{tabular}
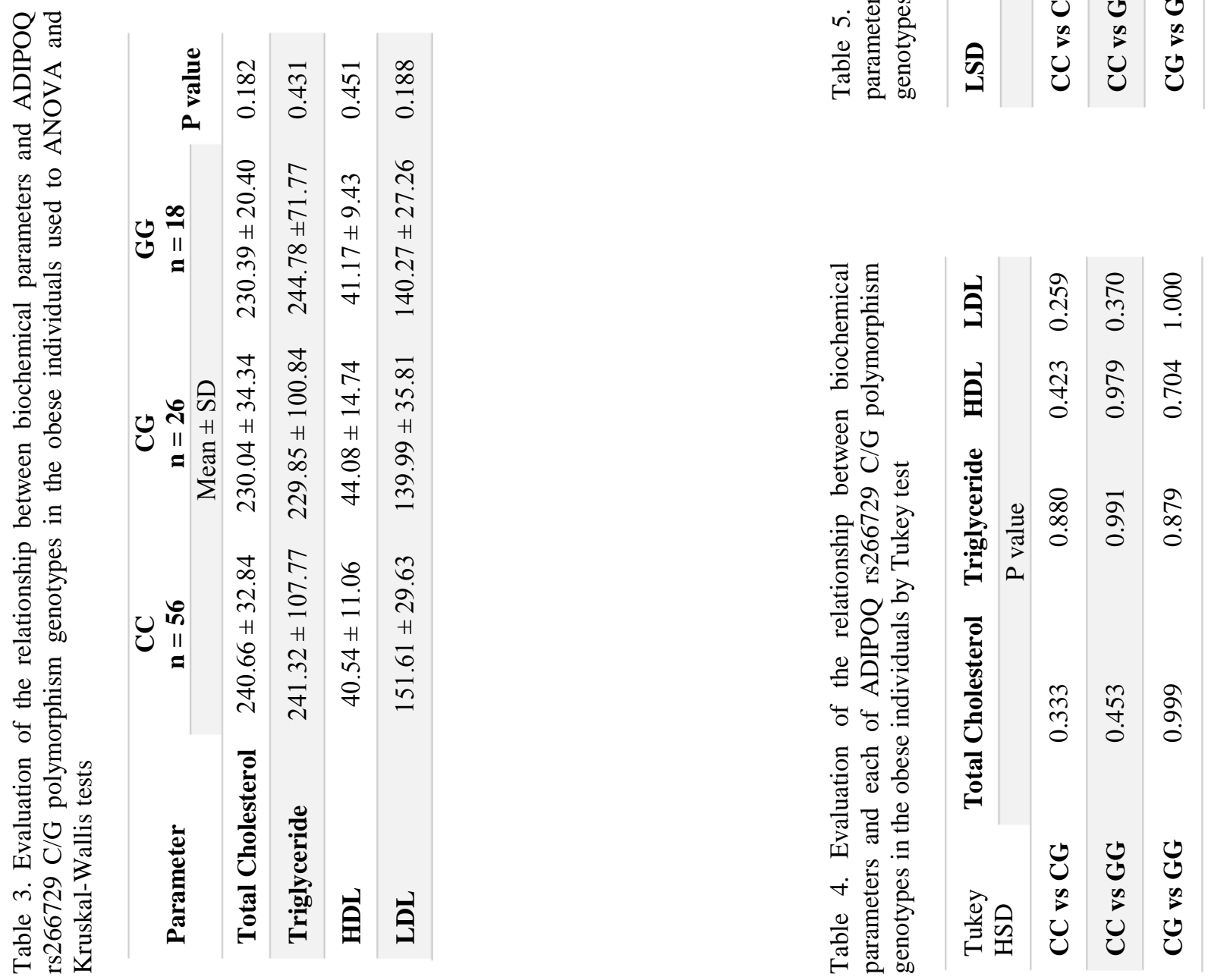


\section{Discussion}

The role of the ADIPOQ gene in controlling the metabolism of lipids and carbohydrates has been confirmed in many studies $(7,27)$. In the present study, we focused on a polymorphism that could play a role in gene expression. The involvement of this polymorphism in related metabolic disorders has been reported in several studies (28-30).

High triglyceride levels and low high-density lipoprotein (HDL) cholesterol levels are of features of the metabolic syndrome which is one of the metabolic syndrome hallmarks of obesity. Elevated levels of small, dense, low-density lipoprotein (LDL) cholesterol particles in plasma are key features associated with high triglyceride and low HDL cholesterol levels in people disposed to gain weight. Accumulation of dense small LDL particles also increases in subjects with abdominal fat accumulation (large waist circumference). In the mechanism of excessive accumulation of intra-abdominal (visceral) fat, elevated levels of total cholesterol and LDL cholesterol, although common, are mainly associated with the consumption of saturated fats, and are not necessarily associated with weight gain and obesity (31).

The importance of parameters including triglycerides, $\mathrm{HDL}, \mathrm{LDL}$, and total cholesterol in relation to obesity has been considered in many studies. For example, Feingold and Granfeld reported that 60 to 70 percent of obese people show blood lipids disturbances, which can indicate LDL, HDL, or triglyceride levels outside the normal range in the blood (32). A study in the Chinese population examined the correlation between HDLc levels and obesity and found a negative association between blood HDLc levels and obesity (33). Klopp et al. demonstrated that obesity increases the risk of cardiovascular disease due to some risk factors such as elevated triglyceride levels, elevated LDL levels, and decreased HDLc levels (34). Dastani et al. showed convincing evidence of an association between several adiponectin-lowering genes and SNP with decreased body mass index (BMI), increased waist-to-hip ratio (WHR), high triglyceride (TG) levels, and low HDL levels (35). Interestingly, in a study of two variants in the ADIPOQ gene promoter, $-11391 \mathrm{G}>\mathrm{A}$ and -11377 $\mathrm{C}>\mathrm{G}$ were associated with abdominal obesity, TG levels, and an increased risk of metabolic syndrome in the young population aged 20-33 years (36). For the first time, a study by Kaftan and Hussein showed an inverse relationship between HDL levels and rs266729 polymorphism in the Iraqi population. This was the first study in which such a relationship has been reported (37). Sun et al. (2008) examined this relationship and found no correlation between circulating HDLlevels and rs266729 polymorphism in the Chinese population (38), which confirms the results of our study. This study shows that especially when performing genetic analysis, the origin of the subjects should be carefully considered and because the genetic variants do not necessarily follow the same pattern among the different populations, the origin of study subjects should be considered. In our results and Tukey and LSD tests, according to Tables 4 and 5 for rs266729 polymorphism, no significant correlation was found between the genotypes of rs266729 polymorphism and biochemical characteristics of obese individuals. The lack of significant differences in the levels of biochemical parameters among the participants indicates accurate sampling, in other words, the lack of specific differences for some reasons such as hormonal diseases or environmental factors in the cause of obesity, for the inclusion of individuals in the study. The variant of rs266729 polymorphism does not show a significant relationship with these characteristics; it can be due to the lack of effect of these variants on changes in adiponectin levels, or the adiponectin level defect may be compensated by other molecules through alternative pathways $(39,40)$. Finally, it should be considered that unstudied polymorphisms involved in the imbalance of association with the genetic variants of adiponectin may also play a role in changes in plasma levels of adiponectin (6).

One of the limitations of our study was the number of samples. In addition, the relationship between $-11,377 \mathrm{C}>\mathrm{G}$ adiponectin gene polymorphism and serum lipid characteristics level of obese subjects needs to be investigated in other populations, also other polymorphisms of adiponectin gene need to be considered.

Our study showed that there is no significant correlation between biochemical parameters including total cholesterol, triglycerides, HDL, and LDL levels with ADIPOQ rs266729 polymorphism. Also, according to the results of our study no significant association between different genotypes of this polymorphism in obese individuals with serum 
levels of total cholesterol, triglyceride, HDL, and LDL was observed. The lack of relevance of these characteristics can be related to their multifactorial nature, such as diet and nutrition.

\section{Acknowledgements}

We thanks Kashan University and Shahrekord University for their supports. Also we thanks Tamin Ejtemaee Clinic, Borujen, Charmahal Va Bakhtiari province of Iran.

\section{Author Contributions}

Laboratory work has done by NR as her MSc thesis, also, collaborated in writing. AMA participated as the group leader and the owner of the idea and the main author of the article. $\mathbf{R N}$ was collaborated as supervisor of thesis in Kashan University. RB was collaborate as advisor of this thesis and sampling and management of participants in this study. All authors read and approved the final version of manuscript.

\section{Conflict of Interests}

The authors declare that they have no competing interests.

\section{Ethical declarations}

The study has been approved by the ethical committee of Kashan University of Sciences.

\section{Financial Support}

Research Director of Kashan University financials for MSc thesis.

\section{References}

1. Albuquerque D, Stice E, Rodríguez-López R, Manco L, Nóbrega C. Current review of genetics of human obesity: from molecular mechanisms to an evolutionary perspective. Mol Genet Genomics. 2015; 290(4):1191-221.

2. Nigro E, Scudiero O, Monaco ML, Palmieri A, Mazzarella G, Costagliola C, et al. New insight into adiponectin role in obesity and obesity-related diseases. Biomed Res Int. 2014; 2014:658913.

3. Greenberg AS, Obin MS. Obesity and the role of adipose tissue in inflammation and metabolism. Am J Clin Nutr. 2006; 83(2):461-5.

4. Reddon H, Guéant JL, Meyre D. The importance of geneenvironment interactions in human obesity. Clin Sci. 2016; 130(18):1571-97.

5. Cao H. Adipocytokines in obesity and metabolic disease. $\mathrm{J}$ Endocrinol. 2014; 220(2):T47-59.

6. Breitfeld J, Stumvoll M, Kovacs P. Genetics of adiponectin. Biochimie. 2012; 94(10):2157-63.

7. Lim S, Quon MJ, Koh KK. Modulation of adiponectin as a potential therapeutic strategy. Atherosclerosis. 2014; 233(2):7218.

8. Alsaleh A, Sanders TAB, O’Dell SD. Effect of interaction between PPARG, PPARA and ADIPOQ gene variants and dietary fatty acids on plasma lipid profile and adiponectin concentration in a large intervention study. Proc Nutr Soc. 2012; 71(1):141-53.

9. Wanders D. Pharmacological effects of lipid-lowering drugs on circulating adipokines. World J Diabetes. 2010; 1(4):116-28.

10. Bouchard C. Gene-environment interactions in the etiology of obesity: Defining the fundamentals. Obesity. 2008; 16 (Suppl 3):S5-S10.

11. Coelho M, Oliveira T, Fernandes R. Biochemistry of adipose tissue: An endocrine organ. Arch Med Sci. 2013; 9(2):191-200.

12. Ntzouvani A, Fragopoulou E, Panagiotakos D, Pitsavos C, Antonopoulou S. Reduced circulating adiponectin levels are associated with the metabolic syndrome independently of obesity, lipid indices and serum insulin levels: a cross-sectional study. Lipids Health Dis. 2016; 15(1):140.

13. Wanders D, Plaisance EP, Judd RL. Lipid-Lowering Drugs and Circulating Adiponectin. In: Vitamins and Hormones [Internet]. 1st ed. Elsevier Inc.; 2012. p. 341-74. Available from: http://dx.doi.org/10.1016/B978-o-12-398313-8.00013-o.

14. Christou GA, Kiortsis DN. Adiponectin and lipoprotein metabolism. Obes Rev. 2013; 14(12):939-49.

15. Zhao T, Zhao J. Genetic effects of adiponectin on blood lipids and blood pressure. Clin Endocrinol (Oxf). 2011; 74(2):214-22.

16. Matsuzawa Y. Adiponectin: Identification, physiology and clinical relevance in metabolic and vascular disease. Atheroscler Suppl. 2005; 6(2):7-14.

17. Shirakawa T, Nakajima K, Yatsuzuka S, Shimomura Y, Kobayashi J, Machida T, et al. The role of circulating lipoprotein lipase and adiponectin on the particle size of remnant lipoproteins in patients with diabetes mellitus and metabolic syndrome. Clin Chim Acta. 2015; 440:123-32.

18. Gibas-Dorna M, Piątek J, Kupsz J, Bernatek M, Krauss H, Sowińska A, et al. Relationship between adipokines and lipid profile in postmenopausal women with different apolipoprotein E genotypes. Women Heal. 2017; 57(8):891-904.

19. Gradinaru D, Margina D, Borsa C, Ionescu C, Ilie M, Costache $\mathrm{M}$, et al. Adiponectin: possible link between metabolic stress and oxidative stress in the elderly. Aging Clin Exp Res. 2017; 29(4):621-9.

20. Eslamian M, Mohammadinejad P, Aryan Z, Nakhjavani M, Esteghamati A. Positive Correlation of Serum Adiponectin with Lipid Profile in Patients with Type 2 Diabetes Mellitus is Affected by Metabolic Syndrome Status. Arch Iran Med. 2016; 19(4):26974 .

21. Durrani S, Shah J, Khan MA, Jan MR. Relationship of adiponectin level with lipid profile in type-2 diabetic men with coronary heart disease. J Ayub Med Coll Abbottabad. 2015; 27(1):32-5.

22. Katsiki N, Mantzoros C, Mikhailidis DP. Adiponectin, lipids and atherosclerosis. Curr Opin Lipidol. 2017; 28(4):347-54.

23. Jafari M, Pirouzi A, Anoosheh S, Farnia P, Tajik N. Rapid and Simultaneous Detection of Vitamin D Receptor Gene Polymorphisms by a Single ARMS-PCR Assay. Mol Diagn Ther. 2014; 18(1):97-103.

24. Huang T, Zhuge J, Zhang WW. Sensitive detection of BRAF V60oE mutation by Amplification Refractory Mutation System 
(ARMS)-PCR. Biomark Res. 2013; 1(1):3. 25. Najafi M, Firoozrai M, Gohari HL, Zavarehie A, Basiri G. Direct haplotyping of bi-allelic SNPs using ARMS and RFLP analysis techniques. Biomol Eng. 2007; 24(6):609-12.

26. Ahlawat S, Sharma R, Maitra A, Roy M, Tantia MS. Designing, optimization and validation of tetra-primer ARMS PCR protocol for genotyping mutations in caprine Fec genes. Meta Gene. 2014; 2:439-49.

27. Vasseur F, Meyre D, Froguel P. Adiponectin, type 2 diabetes and the metabolic syndrome: lessons from human genetic studies. Expert Rev Mol Med. 2006; 8(27):1-12.

28. Ambroziak M, Kolanowska M, Bartoszewicz Z, Budaj A. Adiponectin gene variants and decreased adiponectin plasma levels are associated with the risk of myocardial infarction in young age. Gene. 2018; 642:498-504.

29. Chiodini BD, Specchia C, Gori F, Barlera S, D'orazio A, Pietri S, et al. Adiponectin gene polymorphisms and their effect on the risk of myocardial infarction and type 2 diabetes: An association study in an Italian population. Ther Adv Cardiovasc Dis. 2010; 4(4):22330.

30. Thanasias E, Polychronakis I, Kampen V Van, Brüning T, Merget R. Respiratory Regulation - The Molecular Approach [Internet]. Pokorski M, editor. Dordrecht: Springer Netherlands; 2013. 47-53 p. (Advances in Experimental Medicine and Biology; vol. 756). Available from: http://link.springer.com/10.1007/97894-007-4549-0.

31. Han TS, Lean MEJ. Metabolic syndrome. Medicine (Baltimore). 2015; 43(2):80-7.

32. Feingold KR, Grunfeld C. Obesity and Dyslipidemia. [Updated 2018 Apr 10]. In: Feingold KR, Anawalt B, Boyce A, et al., editors. Endotext [Internet]. South Dartmouth (MA): MDText.com, Inc.; 2000-. Available from: https://www.ncbi.nlm.nih.gov/books/NBK305895/

33. Wang H, Peng DQ. New insights into the mechanism of low high-density lipoprotein cholesterol in obesity. Lipids Health Dis. 2011; 10:1-10.

34. Klop B, Elte JWF, Cabezas MC. Dyslipidemia in Obesity: Mechanisms and Potential Targets. Nutrients. 2013; 5(4):121840.

35. Dastani Z, Hivert MF, Timpson N, Perry JRB, Yuan X, Scott $\mathrm{RA}$, et al. Novel loci for adiponectin levels and their influence on type 2 diabetes and metabolic traits: A multi-ethnic meta-analysis of 45,891 individuals. PLoS Genet. 2012; 8(3): e1002607.

36. Karmelić I, Lovrić J, Božina T, Ljubić H, Vogrinc Ž, Božina N, et al. Adiponectin Level and Gene Variability Are Obesity and Metabolic Syndrome Markers in a Young Population. Arch Med Res. 2012; 43(2):145-53.

37. Kaftan AN, Hussain MK. Association of adiponectin gene polymorphism rs266729 with type two diabetes mellitus in Iraqi population. A pilot study. Gene. 2015 Oct;57O(1):95-9.

38. Sun H, Gong ZC, Yin JY, Liu HL, Liu YZ, Guo ZW, et al. The association of adiponectin allele $45 \mathrm{~T} / \mathrm{G}$ and $-11377 \mathrm{C} / \mathrm{G}$ polymorphisms with Type 2 diabetes and rosiglitazone response in Chinese patients. Br J Clin Pharmacol. 2008; 65(6):917-26.

39. Landecho MF, Tuero C, Valentí V, Bilbao I, de la Higuera M, Frühbeck G. Relevance of leptin and other adipokines in obesityassociated cardiovascular risk. Nutrients. 2019; 11(11):1-16.

40. Rabiee F, Lachinani L, Ghaedi S, Nasr-Esfahani MH, Megraw TL, Ghaedi K. New insights into the cellular activities of
Fndc5/Irisin and its signaling pathways. Cell Biosci. 2020; 10(1):51. 